\title{
COMMUNITY ENGAGEMENT, CHILD WELFARE, AND DOMESTIC VIOLENCE SERVICE AGENCIES
}

\section{Colleen MacPherson}

\begin{abstract}
Although coordinated community responses to domestic violence are widely encouraged in the literature as a best practice approach, collaboration between multiple domestic violence response service agencies and government systems is often not achieved. Because of the fragmentation of domestic violence services, this literature review examines community engagement in general and the need for coordination between child welfare agencies and women serving anti-violence services in particular. The skills and strategies necessary for community engagement are explored along with the historical relationship between the two service streams. Also included is a review of the barriers to collaboration between child welfare and women serving agencies along with recommendations to overcome these hurdles. By way of summation, a discussion is provided on how information learned through this review process may be applied to practice for Child and Youth Care Practitioners and others who take up the difficult task of responding to the complex needs of families experiencing domestic violence.
\end{abstract}

Significant social problems cannot be resolved by any one agency: They require the collaboration of multiple agencies. When problems arise, a single agency can address only the symptom itself, but when efforts are coordinated among agencies, the underlying problem can then be addressed. (Banks, Dutch, \& Wang, 2008, p. 877)

Much of the literature with respect to communities' responses to domestic violence speaks to the need for multiple service agencies and government systems to collaborate in developing appropriate and effective interventions for families who experience domestic violence: interventions that balance support for victims with accountability for perpetrators (Banks, Dutch, \& Wang, 2008; Banks, Landsverk, \& Wang, 2008; Echlin \& Osthoff, 2000; Featherstone \& Peckover, 2007; Friend, 2000; Malik, Ward, \& Janczewski, 2008; Mancini, Nelson, Bowen, \& Martin, 2006; Moles, 2008; Pennell \& Burford, 2000; Schechter \& Edleson, 1995; Spears, 2000). But as Mancini et al. (2006) state, "unfortunately, although communitywide responses to IPV (intimate partner violence) are strongly encouraged, they are rarely obtained" (p. 206). Further, although community resources exist for families experiencing domestic violence, they are rarely organized in ways that are user friendly and easy for clients to access, especially if families have boys older than 14 years of age. Clients face the daunting task of negotiating between disparate and uncoordinated agencies when seeking help for domestic violence (Hardcastle, Wenocur, \& Powers, 1997; Friend, 2000). 
In this literature review, the relationships between child welfare agencies and women serving domestic violence agencies will be explored (women serving agencies include transition homes, stopping the violence counselling programs, children who witness abuse programs, court advocacy and victim assistance programs). The literature review begins with a broader look at the definition of community engagement and then narrows its scope to information about the engagement between child welfare and domestic violence agencies. The focus only on one relationship within the wider context of the multiple relationships involved in a coordinated community response is not intended to communicate to the reader a belief that comprehensive and coordinated community responses for domestic violence (including many service agencies such as the police, courts, victim assistance workers, and multicultural workers) are insignificant. Rather, it is suggested here that the unresolved strain between these two particular groups has been a significant barrier to collaboration between the two service streams and an obstacle to their individual involvement in a coordinated community response; therefore, a coordinated community response is unlikely to be achieved without first building bridges between these two agencies.

This literature review seeks to answer the following questions: What are the knowledge, skills, and strategies necessary for community engagement, in particular for engagement between women serving agencies and child welfare? How has community engagement between the two groups been used in the past? What are the barriers and cautions to engagement? What are the common themes that are revealed in the literature with respect to engagement between child welfare and women serving agencies and, finally, how can the information learned through this review process be applied to child and youth care practice?

\section{Methodology}

This review was conducted using the databases Sociological Abstracts, Academic Search Premier, Women's Studies International, PsycInfo, and the Environmental Index. Also employed were: Medline and Social Work Abstracts. The search terms used were (child welfare or child protection or family services) and (family violence or domestic violence or assault* or antiviolence) and (agenc* or service* or program* or initiative*) and (relationship* or collaborat* or inter-agenc*). ${ }^{1}$

Further searches were conducted using Google Scholar to seek advice from government agency publications regarding collaboration between child welfare - in particular the Ministry of Children and Family Development (MCFD) - and community support agencies. Articles that focus on the collaborative relationships between child welfare and anti-violence agencies were included in this literature review; articles that covered in-depth definitions of the harm to children from exposure to domestic violence were not. This review is based on the premise that the harm from exposure to domestic violence is now widely accepted in both service streams and is well documented in the literature. It is acknowledged that a detailed analysis of the dynamics of domestic violence and the harm to children is beyond the scope of this review.

1 Credit for the article searches (excluding Google Scholar) belongs to the staff at the University of Victoria's Infoline. 


\section{Defining Community Engagement/Collaboration}

Community engagement as defined by the North American Certification Project (NACP) (Mattingly, Stuart, \& VanderVen, 2002) is listed as part of the broader domain of "Developmental Practice Methods" (p. 30). According to this document's competency standards, professional Child and Youth Care Practitioners are competent in the skill of engaging communities when they can demonstrate the following activities:

- Access up-to-date information about service systems, support and advocacy resources, as well as community resources, law, regulation, and public policy.

- Demonstrate the ability to initiate, create, and sustain collaborative relations with other organizations and persons.

- Facilitate client contact with relevant community agencies.

Since those competencies that speak to engagement with families and individuals are listed in separate sections of the document, it is assumed that community engagement is considered a separate and distinct, but equally important skill set for caring for families within their contexts. Others have also identified community engagement as a fundamental activity of human service professionals in their efforts to support the development of families (Butcher et al., 2003; Hardcastle et al., 1997; Hashagen, 2002; Midgley \& Livermore, 1998; Skotnitsky \& Ferguson, 2005; Tastsoglou \& Miedema, 2003). Atherton, Hashagen, Garratt, and West (2002) state that community planning (engagement) is a process of public, private, and voluntary agencies coming together under one vision to streamline, integrate, and improve service delivery. In addition, these authors acknowledge that the key aspect of successful community collaboration is sensitivity to the needs and concerns of all parties involved. Atherton et al. (2002) also suggest that collaboration rarely occurs spontaneously, but rather flows from some form of intentional development, and point out that some collaborators will be motivated to become involved in the efforts immediately, while others will need time and encouragement to actively participate. As well, Skotnitsky and Ferguson (2005) argue that collaboration between service agencies is essential in building a community's capacity to meet the needs of its members.

As Mancini et al. (2006) point out, "the shared responsibility and collective competence that emerge from community members banding together can become a powerful and ongoing positive influence on the quality of community life, including the relationship between intimate partners" (p. 204). They argue for active, collaborative interventions to prevent domestic violence and indicate that the legal reforms (mandatory charging for perpetrators and recognition in child welfare legislation that exposure to violence may constitute child maltreatment) that have taken place over the last two decades in North America have not been sufficient to prevent domestic violence. This suggests the need for cultural and community reforms. Consequently further sections in this literature review will focus on the cultural differences between child welfare and women serving agencies and ways to bridge the divide.

\section{Defining the Need for Engagement and Collaboration Between Child Welfare and Women Serving Agencies}

Moles (2008) notes that until recently child protection agencies did little to intervene or to support women and children when violence was being perpetrated against the mother. In 
addition, Davies and Krane (2006) note that "recent recognition of the effects of domestic violence on children has given rise to calls for collaborative interventions between arenas of child protection and domestic violence" (p. 412). Davies and Krane define a child's exposure to domestic violence as more than directly witnessing violence toward their parent, usually their mother. For these authors, exposure also includes being witness to the aftermath, including the arrest of the perpetrator, being threatened, being used as pawns, or even being kidnapped and taken hostage. Friend (2000) states that UCLA's domestic violence/child abuse initiative operates on the premise that "domestic violence is child abuse" (p. 258). Moreover, several authors note the overlap between child maltreatment and wife assault and estimate that $30 \%$ to $60 \%$ of men who batter their partners also abuse their children (Findlater \& Kelly, 1999; Malik et al., 2008; Nuszkowski et al., 2007). This statistic highlights the need to increase communities' capacity to respond to domestic violence and the need for collaboration between the efforts of those protecting children and those advocating for women who have experienced violence at the hands of their partners (Schechter \& Edleson, 1995).

Schechter and Edleson (1995) pose the question, "can we really help or protect children if we ignore the mother?" (p. 1). Canadian and American child welfare agencies are developing policies and procedures with respect to collaborative efforts of both service groups (Cory, AbiJaoude, Baldwin, Bernt, \& Mortensen, 2008; Findlater \& Kelly, 1999). Given that six out of ten Canadian provinces have legislation that clearly defines a child's exposure to domestic violence as grounds for needing protection, it is essential for groups addressing domestic violence to work together to ensure that families' service needs are met, according to Echlin and Osthoff (2000). They state, "What is clear, however, is that women and children are suffering both by the perpetrators of abuse and as a result of inadequate societal protection" (p. 211).

Nuszkowski et al. (2007) argue that because domestic violence has detrimental effects for both victims and communities, the onus of responsibility should not be borne by just child welfare agencies or agencies providing relief from domestic violence to women and their children. A collaborative community-wide effort is warranted. These authors, like many others, are calling for a shared commitment to ending violence within families despite any tensions caused by the different mandates of child welfare and women serving agencies, and for an end to an approach that positions the protection of children and the protection of women against one another. Schechter and Edleson (1995) have noted since 1994 that the most difficult cases that challenge child welfare and domestic violence agencies are the cases they share together, cases in which the father is using severe violence against the mother and children or where mothers and children are living under the threat of further violence even though the father is no longer in their lives. Often, the legacy of the violence lives on in the mother's or children's behaviour, manifested as teen violence toward the mother, the mother's coercive or physical punishment of the children, and/or mental health and addiction issues of either the mother or children.

In June of 2000, a partnership of British Columbia provincial organizations submitted a discussion paper to the former Ministry of Children and Families that outlined critical issues faced by women and children who were victims of, or exposed to domestic violence (Ministry of Children and Family Development, 2004). The results from an ensuing consultation process between provincial ministries including the Ministry for Children and Families, the Attorney General, and Health and Women's Equality indicated that mothers, youth, and children were not utilizing the available safety, counselling, and medical resources due to their reluctance to 
become involved with these government ministries. Community service agencies provided the explanation for this reluctance to seek help and support: Some ministry interventions were compromising women's and children's safety instead of ensuring it (Ministry of Children and Family Development, 2004, p. 19). An outcome of the consultation process was a call for a collaborative effort between private and public stakeholders in domestic violence prevention to develop best practice approaches for child protection interventions in situations where mothers were the victims of domestic violence (Ministry of Children and Family Development, 2004). Further outcomes of the consultation process were the development of the following documents: Best Practice Approaches: Child Protection and Violence Against Women (Ministry of Children and Family Development, 2004); and Child Protection and Violence Against Women: A Curriculum for Child Protection Workers (Cory et al., 2008).

Numerous authors have emphasized the belief that a collaborative approach to interventions with families experiencing domestic violence is the optimal way to achieve safety for women and children and accountability for the offender (Banks, Dutch, \& Wang, 2008; Banks, Landsverk, \& Wang, 2008; Government of British Columbia 2008; Featherstone \& Peckover, 2007; Malik et al., 2008; Ministry of Community Services, 2005; Pence \& Shepard, 1999). With respect to the experiences of Aboriginal women, a collaborative approach to domestic violence may be even more significant as Aboriginal women in Canada experience three times the amount of spousal violence than non-Aboriginal women and are eight times more likely to die from that violence (Ministry of Community Services, 2005). Jessica Ball (2007) states that, "most communities in Canada today maintain an individual-centered and nonintegrated approach to family and children's services" (p. 3). This is particularly troublesome in First Nations communities, as Ball points out that services are often not even located in the communities themselves. The services are distanced administratively, culturally, socially, and geographically from the people they are meant to serve. Despite the general consensus in the literature that a coordinated collaborative approach is the most effective response in ensuring safety and accountability, there are many barriers to this practice. "Understanding how to manage the problem of family violence at the community level, however, has been significantly more difficult than acknowledging the need to do so" (Malik et al., 2008, p. 934).

\section{Barriers and Cautions}

As noted above, the literature indicates that there are multiple ideological, systemic, and individual barriers to engagement between child welfare agencies and women serving agencies. Traditionally there has been little cooperation between child welfare and women serving agencies to collaboratively develop safe and effective responses and interventions for families experiencing domestic violence. Numerous authors refer to the strained relationship between the two agencies (Friend, Lambert, \& Shlonsky, 2007; Echlin \& Osthoff, 2000; Findlater \& Kelly, 1999; Malik et al., 2008; Schechter \& Edleson, 1995). Findlater and Kelly (1999) state, "mistrust was common, noncooperation the rule" (p.167) and go on to note the tendency of each type of agency to find fault with the other. Additionally, they point out that in general, child protection workers traditionally believed that domestic violence workers advocated exclusively for women's safety, while domestic violence workers believed that protection workers privileged children's safety to the exclusion of women's. Evidence of this unhelpful positioning is echoed by Friend et al. (2007), Malik et al. (2008), and Moles (2008). Moles notes that domestic violence agencies traditionally have shown a reluctance to engage with child welfare agencies 
due to a perception among women serving agency staff that child protection workers were unable or unwilling to be sensitive to abused mothers and the challenges they face in keeping themselves and their children safe. Fortunately, there is also evidence provided by Schechter and Edleson (1995) that these perceptions are slowly giving way to a desire for the two groups to work together to end violence within families.

Malik et al. (2008) note that the seemingly conflicting mandates and roles of child welfare and women serving agencies can be made worse by the fact that child welfare agencies are funded and governed by the state while domestic violence agencies are usually non-profit societies and have far fewer financial resources at their disposal. In addition, women serving agencies grew out of the grassroots feminist advocacy movement when traditional government systems failed to protect women (Malik et al., 2008). The tension caused by this failure to protect women is still evident in the relationships between the two kinds of service agencies. In addition to the disparate focus of the two agency types, there are also opposing views within the agencies of who is the primary victim: the woman or the child (Friend et al., 2007). Friend et al. (2007) refer to these differing views as a kind of "culture clash" and point out that service providers may be so immersed in their own systems, ideology, and missions that they are unable to embrace a more holistic and collaborative approach to caring for women and children (p. 345). The traditional child welfare view of domestic violence has been that domestic violence is symptomatic of stress and marital conflict and the ensuing interventions deemed appropriate reflected these notions: couples therapy and/or individual counselling (Friend et al., 2007). These interventions have been criticized by women serving agencies as putting the women and children at greater risk as the power imbalances between perpetrator and victim are played out in couples counselling while offenders are not held accountable for their purposeful use of violence. As Friend (2000) notes, the way a problem is framed is fundamentally important, as it will inform the ways in which we will respond to the problem.

Friend et al. (2007) point out that another barrier between child welfare and women serving agencies is the lack of effective interventions for men who use violence against their partners, and suggest that, "It does little good to identify a problem for which there is little solution" (p. 352). Most domestic violence workers are aware of the lack of programs to which a child protection worker can refer men so that they can learn accountability. Some believe the lack of resources for perpetrators is a reflection of the willingness of government funders to allow domestic violence to continue to be a women's problem rather than a social justice issue that is owned jointly by government and society and by women and men.

Featherstone and Peckover (2007) argue that the lack of attention to the perpetrators of domestic violence by the community and child welfare, as evidenced by the lack of interventions and services for violent fathers, also creates a barrier between child welfare agencies and women serving agencies. These authors express the concern that the lack of focus on violent fathers ultimately results in women being “expected and left to manage violent men's behaviour and the consequences of such behaviour" (p. 195). They further argue that society is missing out on opportunities to engage with violent fathers, which does not serve the support or protection needs of mothers and children. This is particularly concerning, considering the challenges faced by the criminal justice system in securing convictions for such fathers and in mandating them to attend violence treatment programs. It is also important to note that few violence treatment programs focus on violent men's fathering or their everyday involvement in their families. Women serving 
agencies know all too well the negative impact that a violent father can have on the lives of his children and their mother (Featherstone \& Peckover, 2007).

Mancini et al. (2006) note there are numerous attitudes and societal norms that reinforce domestic violence including the notion that intimate partner violence is private or even deserved by the victim. Historically, it has been a common experience for women to be blamed by child welfare workers for both their own victimization and their "failure to protect" their children from their partner's violence (Friend, 2000). These attitudes and norms have led to women serving agencies taking up the challenge to protect women (and their children) from systems that have failed to do so, including child welfare and the criminal justice system (Banks, Dutch, \& Wang, 2008; Moles, 2008).

Banks, Dutch, and Wang (2008) state that collaboration requires "change across multiple agencies and across multiple levels within those agencies" (p. 878). They further point out that child welfare and women serving agencies are already overtaxed, and identify the following systemic barriers to engagement between the two service groups: lack of consensus between the agencies with respect to best practice approaches and philosophies, lack of communication between agencies, lack of commitment and support from senior management, lack of strong leadership, and lack of adequate resources, time, and training. As with other authors, Banks, Dutch, and Wang also identify the negative stereotypes held by individual workers toward potential colleagues in other agencies as barriers to collaboration, e.g., all social workers are punitive and all domestic violence workers are radical anti-establishment feminists.

Malik et al. (2008) state that concerns regarding client confidentiality are also barriers to engagement between child welfare and women serving agencies. Domestic violence workers are often worried that revealing domestic violence to child welfare workers may inadvertently trigger punitive actions toward the non-offending mother, that is, to the mother being blamed by the child protection worker for the violence or the mother being accused of failing to protect her children. As further barriers to collaboration between different kinds of agencies, Malik and colleagues also point to concerns about power sharing between agencies, the lack of authority faced by domestic violence workers in the collaborative process, and the possibility that the goals of each agency may have the potential for causing harm to either child or parent.

Finally, the beliefs of individual workers have been identified as barriers to engagement between child welfare and women serving agencies. An individual's beliefs with respect to the oppression of women, the role of mothers, the best interests of children, and the accountability of men have been recognized by Echlin and Osthoff (2000) as potential obstacles. As they state, "The variations in attitudes, awareness, laws and practices result in fragmented responses to women and children exposed to women abuse" (p .210).

The review of the literature revealed three significant cautions for those considering increasing engagement and collaboration between child welfare and women serving agencies. Friend et al. (2007) argue that their review of the literature indicated that many, if not all, interventions used by child welfare workers and domestic violence workers do not eradicate violence and therefore if violence cannot be stopped altogether perhaps a harm reduction approach might be more effective. A harm reduction approach is defined by Pennell and Burford (2000) as "a set of strategies designed to encourage individuals to move toward an ideal (no violence) or to at least mitigate the harm caused to themselves and others if the behaviour 
continues (safety planning)" (p. 357). Friend et al. (2007) offer the caution that although child welfare agencies, including MCFD, are currently utilizing community-based harm reduction approaches such as family group conferencing, very little has been written about a harm reduction approach to domestic violence. They surmise that this is due to the double-edged sword of child protection interventions that embrace a harm reduction approach: Children are sometimes left in unsafe situations while removal of a child causes its own kind of harm.

A second caution is offered by Davies and Krane (2006). In the quest to develop collaboration between child welfare and women serving agencies, the mother's experience may be lost and that without including the mothers in the collaborative process, the potential is there to further disempower and overburden mothers who are already struggling to care for and protect their children. These authors further note that the absence of the mothers in the process can reinforce the problematic practice of mother blaming. The third caution offered by Davies and Krane (2006) is a warning to both child welfare and women serving agency workers with respect to pressuring a woman to leave or to stay with a violent partner, as there are significant risks associated with each course of action: There is a direct correlation between wife assault and child abuse when the family stays intact, versus the increased risk of homicide and assault toward a woman when she leaves a violent partner. Both sets of risks must be addressed with safety planning (p. 416).

\section{Skills and Strategies}

Despite the barriers to engagement between child welfare and women serving agencies, there is considerable common ground between the two groups that provides a fertile environment for growth. Although traditionally child protection workers have focused attention either on creating safe environments for children within their families or removed them, while women serving agencies have provided safe havens and programs for women and their children, both agencies have the promotion of safety as their bottom line (Pennell \& Burford, 2000).

Some authors in the current literature suggest alternative community-based child welfare responses to domestic violence (Carrillo \& Carter, 2001; English, Wingard, Marshall, M. Orme, \& A. Orme, 2000; Pennell \& Burford, 2000). Pennell and Burford (2000) point out that "with rising demands on child welfare, workers need to consider new options, including strategies that promote a collaborative effort of family, community and government. Family group conferencing (FGC) integrates efforts to advance child and adult safety and strengthens family unity while expanding its meaning" (p. 131). FGC is a process that brings together families, child welfare workers, and community support people (including women serving agency staff) to develop a plan to resolve abuse, neglect, and violence. Before the plan is implemented, it must be approved by the child welfare agency to ensure that it promotes child safety. Although English et al. (2000) found alternative community-based collaborative strategies such as the voluntary FGC program to be useful for families at lower risk of child abuse and neglect associated with domestic violence, they also warned that such voluntary strategies will not increase child safety if there is not an obvious recognition by the families of the risks and a clear articulation of the motivation to change (p. 387). 
Hardcastle et al. (1997) argue that the most effective case management model for child protection workers includes referral and collaboration with community services including domestic violence agencies. The authors also note that in order for the engagement between child welfare and community service agencies to be effective, the influential aspects of the relationships between the two groups should be taken into account. The factors that influence collaborative relationships are identified as power balances, rules of information exchange, and individual and group ideologies that include values, beliefs, and feelings (Halseth \& Lo, 1999). Other authors suggest cross-training between the two service groups as essential for bringing these differences between agencies' mandates, policies, and practices into prominence (Coben, 2007; Government of British Columbia, 2008; Cory et al., 2008; Findlater \& Kelly, 1999; Ministry of Community Services (2005); Moles, 2008).

Findlater and Kelly (1999) posit that, "domestic violence service providers need to be educated about the child welfare system and issues of child abuse and neglect while child welfare workers need to understand issues of domestic violence. And they need to work together to keep children and their mothers safe and hold perpetrators of family violence responsible for their behaviour" (p. 168). Cross-training accomplishes this outcome in addition to ensuring that workers do not have false assumptions and expectations of what agencies can and should achieve. Cross-training also elucidates that child and adult safety is a common goal of child welfare and women serving agencies and the best way to promote child safety is to ensure the mother's safety; the shared goal is then translated into shared practice. Skotnitsky and Ferguson (2005) argue that ideal learning takes place when people are actively involved in exploring a given challenge together.

Findlater and Kelly (1999) also point to the importance of developing cross-training curriculums and best practice approaches and policies similar to the document, Best Practice Approaches: Child Protection and Violence Against Women, created by multiple community service agencies and the Ministry of Children and Family Development (2004), and the document, Child Protection and Violence Against Women: A Curriculum for Child Protection Workers, written by Cory et al. (2008). In support of the cross-training strategy, Nuszkowski et al. (2007) found that child welfare workers who received training on domestic violence were less likely to use interventions that actually decrease the safety of women and children, such as referrals to family preservation programs or couples counselling. In addition, the findings of these authors indicate that child welfare workers were less likely to believe that the women benefited from the abuse, that woman abuse is justified, or that mothers were failing to protect their children when partners used violence toward them. As well, child protection workers recognized women's fear of losing custody of their children to violent fathers as a barrier to leaving relationships with violent partners. Moreover, Nuszkowski et al. (2007) found that child welfare workers were more disposed to engage with violent fathers by referring them to specialized treatment programs. This reflects Featherstone and Peckover's (2007) notion that it is critical to women's and children's safety to engage with violent fathers. Although Nuszkowski et al. (2007) strongly argue for cross-training between child welfare and women serving agencies, they comment that independent operations are the norm for both agencies and therefore developing policies that support collaboration and engagement is likely the most significant influence to collaborative initiatives like cross-training, and ongoing consultation and communication between the two groups. In other words, engagement between the two groups is not likely to succeed without the support of the leadership of the two types of agencies. 
Banks, Dutch, and Wang (2008) articulated the most comprehensive list of skills, attributes, and strategies required by front line workers and management for effective interagency collaboration:

- Significant investment of time and resources;

- Awareness and acceptance of an incremental approach to change between the collaborating agencies;

- Agreed-upon timetable for change;

- Joint projects that link shared goals into practice;

- Ability to share resources for joint projects including administrative support and extra time allotted to staff to implement projects;

- Recruitment of staff with the appropriate knowledge and skills (child protection and domestic violence);

- Appropriate support and supervision for staff;

- Willingness to monitor and evaluate services provided;

- Well-defined roles and responsibilities;

- Clear lines of accountability;

- Effective communication between all levels within agencies and between agencies; and

- "Institutional empathy", which the authors define as the understanding of the context and environment that informs the other agencies' practice with women and children.

In addition to skills and strategies that can be adopted between agencies to increase their collaboration, professionals can advocate for societal, legislative, and policy changes that will result in more effective collaborative responses to domestic violence. Echlin and Osthoff (2000) list the following as strategies to enhance collaboration:

- Defining woman abuse as a societal problem;

- Increasing awareness of both child welfare workers and domestic violence workers of the harm done to children from exposure to domestic violence;

- Developing consistent policy for child welfare agencies that will enhance child safety by supporting the non-offending parent and holding the perpetrator accountable for their use of violence;

- Advocating for changes to family relations legislation (child custody and access) and child protection legislation to mirror the experiences of women and children related to violence and abuse;

- Cross-training between child protection and domestic violence agencies; and

- Advocating for a criminal justice system that holds perpetrators responsible for stopping their violence against women.

The review of the literature also revealed some broad suggestions for strengthening community capacity to prevent violence against women and children. These suggestions include supporting community-based services, educating the community, promoting women's economic security, providing support to Aboriginal women, collaborating with the health care system, cross-training between all stakeholders including community service agencies, child welfare, criminal justice systems, and health care systems (Ministry of Community Services, 2005). 
Schecter and Edleson (1995) observe that the best collaboration occurs between child welfare and women serving agencies when there is an agreement that keeping mothers and their children together is the best outcome in most cases. The authors challenge child protection and domestic violence workers to become allies rather than competitors in keeping women and children safe. In addition, Malik et al. (2008) suggest developing a climate of inclusion where power is shared equally between child welfare and women serving agencies as a strategy for overcoming the barriers to collaboration between the two groups. This writer is sceptical that equal power-sharing will or should occur as only child welfare agencies currently have the legal mandate and responsibility to ensure child safety and would be held accountable by the public should harm come to a child once an intervention had been initiated. Although both agencies share the philosophy of and moral responsibility for protecting women and children, they do not share equal legal responsibility.

\section{Conclusions and Discussion}

There is a wealth of literature that defines the need for and the barriers to collaboration between child welfare and domestic violence agencies including the historical development of tensions between the two service streams; there is far less information on overcoming these barriers. The problem has been clearly defined, the solutions warrant more exploration, particularly with respect to providing coordinated and culturally sensitive services for Aboriginal women.

Although much of the literature recognizes that tensions exist between child welfare and domestic violence agencies, only one article named the tensions as "hostility" between the two groups (Findlater \& Kelly, 1999). As a Child and Youth Care Practitioner who has worked in both service sectors, this writer believes that "tensions" is a euphemism for the animosity that can occur between workers of the different agencies. This writer suggests that this hostility is the single greatest barrier to collaboration between the two agencies and that extending the olive branch is a crucial first step in developing effective partnerships to meet the needs of women and children who have experienced violence within their families. It is highly improbable to expect co-creation and collaboration with regard to violence and abuse interventions if the collaborating parties themselves are behaving in ways that are less than cooperative and congenial.

In addition, "before collaborative interventions can succeed, the complexities inherent in the issues facing mothers living with domestic violence must be addressed" (Davies \& Krane, 2006, p. 421). Cross-training between the two service groups as suggested by this literature review would accomplish that first step to successful collaboration. Furthermore, Featherstone and Peckover (2007) suggest that missing the opportunities to engage with violent fathers does not serve the support or protection needs of mothers or children. Much more work is needed in this direction. These are the beginning points for collaboration and can be taken up by any worker regardless of the context in which they work. Further words of wisdom by Alan Pence (2003) are offered to practitioners wishing to collaborate in order to develop communities' capacity to meet the needs of its members in the following passage:

Over the years, I have come to believe that "not knowing" and not taking the lead in a child and youth care situation can be one of the most effective ways to proceed. This is not to say that a professional should not possess knowledge, nor be prepared to bring such knowledge to an interaction, but it is a caution to wait, to let your "professional 
soul", your "en-trained impulse" be still. And perhaps in that stillness, in that space between your knowledge and the other's, something other than your idea and perhaps something other than the other's idea will begin to take shape, fed by forces neither can claim but both can appreciate. (p. 317)

These words reflect this writer's notion that the most important strategy for collaboration between child welfare and women serving agencies is not a strategy at all but rather an attribute of the individual workers: the humility and courage of one to fully embrace the experience, knowledge, and skill of the other. There are many opportunities to build collaborative practice upon the foundation of common ground between child welfare and women serving agencies: a shared belief in safety, the empowerment of non-violent parents, accountability for perpetrators of domestic violence, and the disruption of the transmission of family violence from one generation to another (Moles, 2008). 


\section{References}

Atherton, G., Hashagen, S., Garratt, C., \& West, A. (2002). Involving local people in community planning in Scotland. London: Community Development Foundations Publications.

Ball, J. (2007). Centering community services around early childhood care and development: Promising practices in First Nations. Unpublished manuscript.

Banks, D., Dutch, N., \& Wang, K. (2008). Collaborative efforts to improve system response to families who are experiencing child maltreatment and domestic violence. Journal of Interpersonal Violence, 23(7), 876-902.

Banks, D., Landsverk, J., \& Wang, K. (2008). Changing policy and practice in the child welfare system through collaborative efforts to identify and respond effectively to family violence. Journal of Interpersonal Violence, 23(7), 903-932.

Butcher, J., Howard, P., Labone, E., Bailey, M., Groundwater, S. S., McFadden, M., et al. (2003). Teacher education, community service learning and student efficacy for community engagement. Asia-Pacific Journal of Teacher Education, 31(2), 109-124.

Carrillo, R., \& Carter, J. (2001). Guidelines conducting family team conferences when there is a history of domestic violence. San Franscisco: Family Violence Prevention Fund and the Child Welfare Policy and Practice Group.

Coben, J. H. (2007). Training, co-training, and cross training of domestic violence and child welfare agencies: Reply. Families in Society, 88(4), 35-41.

Cory, J., Abi-Jaoude, A., Baldwin, M., Bernt, L., \& Mortensen, J. (2008). Child protection and violence against women: A curriculum for child protection workers. Victoria, BC: Ministry of Children and Family Development.

Davies, L., \& Krane, J. (2006). Collaborate with caution: Protecting children, helping mothers. Critical Social Policy, 26(2), 412-425.

Echlin, C., \& Osthoff, B. (2000). Child protection workers and battered women's advocates working together to end violence against women and children. Journal of Aggression, Maltreatment \& Trauma, 3(1), 207-219.

English, D. J., Wingard, T., Marshall, D., Orme, M., \& Orme, A. (2000). Alternative responses to child protective services: Emerging issues and concerns. Child Abuse \& Neglect, 24(3), 375-388.

Featherstone, B., \& Peckover, S. (2007). Letting them get away with it: Fathers, domestic violence and child welfare. Critical Social Policy, 27(2), 181-202. 
Findlater, J. E., \& Kelly, S. (1999). Reframing child safety in Michigan: Building collaboration among domestic violence, family preservation, and child protection services. Child Maltreatment, 4(2), 167-174.

Friend, C. (2000). Aligning with the battered woman to protect both mother and child: Direct practice and policy implications. Journal of Aggression, Maltreatment \& Trauma, 3(1), 253267.

Friend, C., Lambert, L., \& Shlonsky, A. (2007). From culture clash to new possibilities: A harm reduction approach to family violence and child protection services. Brief Treatment \& Crisis Intervention, 7(4), 345-363.

Government of British Columbia. (2008). Keeping women safe: Eight critical components of an effective justice response to domestic violence. Victoria, BC: Critical Components Project Team.

Halseth, G., \& Lo, L. (1999). New voices in the debate: The Quesnel women's resource centre and sustainable community development. Forestry Chronicle, 75(5), 799-804.

Hardcastle, D. A., Wenocur, S., \& Powers, P. R. (1997). Community practice: Theories and skills for social workers. New York: Oxford University Press.

Hashagen, S. (2002). Models of community engagement. Edinburgh: Scottish Community Development Centre.

Malik, N. M., Ward, K., \& Janczewski, C. (2008). Coordinated community response to family violence: The role of domestic violence service organizations. Journal of Interpersonal Violence, 23(7), 933-955.

Mancini, J. A., Nelson, J. P., Bowen, G. L., \& Martin, J. A. (2006). Preventing intimate partner violence: A community capacity approach. Journal of Aggression, Maltreatment \& Trauma, 13(3), 203-227.

Mattingly, M., Stuart, C., \& VanderVen, K. (2002). North American certification project (NACP): Competencies for professional child and youth work practitioners. Journal of Child and Youth Care Work, 17, 16-49.

Midgley, J., \& Livermore, M. (1998). Social capital and local economic development: Implications for community social work practice. Journal of Community Practice, 5, 29-40.

Ministry of Children and Family Development. (2004). Best practice approaches: Child protection and violence against women. Victoria, BC: Author.

Ministry of Community Services. (2005). Community guide for preventing violence against women. Victoria, BC: Author. 
Moles, K. (2008). Bridging the divide between child welfare and domestic violence services: Deconstructing the change process. Children \& Youth Services Review, 30(6), 674-688.

Nuszkowski, M. A., Coben, J. H., Kelleher, K. J., Goldcamp, J. C., Hazen, A. L., \& Connelly, C. D. (2007). Training, co-training, and cross-training of domestic violence and child welfare agencies. Families in Society, 88(1), 35-41.

Pence, A. R. (2003). Thoughts on promoting capacity in support of child well-being. Child \& Youth Care Forum, 32(6), 313-318.

Pence, E., \& Shepard, M. (Eds.). (1999). Coordinating community responses to domestic violence: Lessons from Duluth and beyond. Thousand Oaks, CA: Sage Publications, Inc.

Pennell, J., \& Burford, G. (2000). Family group decision making: Protecting children and women. Child Welfare, 79(2), 131-158.

Schechter, S., \& Edleson, J. L. (1995). In the best interest of women and children: A call for collaboration between child welfare and domestic violence constituencies. Protecting Children, 11(3), 6-11.

Skotnitsky, L., \& Ferguson, E. (2005). Building community capacity with non-profit boards in the inner city. Canadian Journal of Urban Research, 14(1), 32-53.

Spears, L. (2000). Building bridges between domestic violence organizations and child protective services. Harrisburg, PA: National Resource Center on Domestic Violence.

Tastsoglou, E., \& Miedema, B. (2003). Immigrant women and community development in the Canadian Maritimes: Outsiders within? Canadian Journal of Sociology, 28(2), 203-234.

Colleen MacPherson has been a Child and Youth Care practitioner since 1996. She has worked as a front-line crisis support worker and family support worker in the non-profit sector. She is currently employed as a child protection worker with the public service and is completing her M.A. in Child and Youth Care at the University of Victoria. She is the recipient of a University of Victoria Fellowship and recently received a SSHRC Joseph Armand Bombardier Canada Graduate Scholarship to complete her thesis research which explores child welfare responses to the parenting behaviours of men who batter. Colleen's interests are focussed on enhancing both child welfare responses to families requiring support and intervention for domestic violence and collaboration between the private and public sectors. 